\section{Citations: rankings weigh against developing nations}

SIR - Scientists and whole institutes are frequently judged by the number of citations of their papers in scientific journals, and project funding depends on it. But, as Clint Kelly and Michael Jennions note in Correspondence (' $\mathrm{H}$-index: age and sex make it unreliable' Nature 449, 403; 2007), the context and relevance of citations are crucial in reaching this judgement.

Researchers from developing nations often face another problem. In the name of local issues and the national interest, they are required to publish in national journals that rarely find a place among cited journals and have a very limited circulation abroad.

For example, a study of the Thomson Scientific Essential Science Indicators (ESI) during the past five years has found that the National Geophysical Research Institute (NGRI) in Hyderabad, India, scores among the top $1 \%$ of institutions publishing in the geosciences. During this period, the NGRI had 2,338 citations of 657 papers (www.incites.com/institutions/2007menu.html). But if it had not published more than half its publications in national journals - not all of which figure in the ESI database - the NGRI could have been ranked even nearer the top.

In formulating their criteria, publications from institutes and by individuals in local and national journals should also be taken into account: this could be done by assigning some weighted average. The total number of publications in national journals not counted by the ESI would then be considered and weighted in order to arrive at a more appropriate index.

\section{C. Mishra}

National Geophysical Research Institute, Uppal Road, Hyderabad 500 007, Andhra Pradesh, India

\section{Citations: poor practices by authors reduce their value}

SIR - On 22 November, the Higher Education Funding Council for England announced that the assessment and funding of science-based disciplines will in future be "based on citation rates per paper, aggregated for each subject group at each institution" (www.hefce.ac.uk/Pubs/HEFCE/ 2007/07_ 34/07_34.pdf).

Changes in performance indicators always strongly influence individual and institutional behaviour and 'citation gameplaying' will no doubt become a staple of coffee-room conversation. What is less clear is how the citation practices of authors may influence bibliometric indicators.

Citation practices are known to be imperfect. The documented problems include excessive citation of an author's own work. Papers cited can be inappropriate or ambiguous in their support and, in some cases, the authors may not have read the papers they cite. Authors may form 'citation coalitions' within research networks. They may fail to provide citations to intellectual precursors or to work reporting conflicting conclusions. There are geographical and language biases. The increasing number of many-authored papers makes it impossible to have a clean-cut general metric in which one author is associated with one paper.

Taken together, these factors represent a problematic degree of error for the proposed bibliometric system of assessment. They place added responsibility on journal editors and reviewers as arbiters of appropriate author conduct.

Unfortunately, there are no simple solutions. Currently, identifying poor citation practices is not emphasized in the peer-review process, so perhaps journals could adopt a system of random citation audits, or periodically request evidence of citation appropriateness from authors. In reality, time constraints and the sheer volume of submissions to many journals mean that such measures are unlikely to be implemented soon.

Until referencing practices improve, we would argue that using citation rates to assess performance is fundamentally flawed.

Peter A. Todd ${ }^{\star}$, Richard J. Ladle ${ }^{\prime}$

${ }^{\star}$ Department of Biological Sciences, National University of Singapore, 14 Science Drive 4, 117543, Singapore †Oxford University Centre for the Environment, Dyson Perrins Building, South Parks Road, Oxford OX130Y, UK

\section{Glacier programme shows the value of 'ground truth'}

SIR - On-the-ground monitoring is undervalued, as Euan Nisbet points out in his Commentary 'Cinderella science' (Nature 450, 789-790; 2007). Long-term monitoring data provide the critical foundation we need in order to develop an understanding of the processes at work. This, in turn, enables modelling studies and rationally based management decisions. That is why having 'ground truth' - information gathered on the spot - to combine with satellite observations and modelling is even more critical today.

Through the 1980s and 1990s, we saw a deterioration in many key long-term monitoring programmes, the best example being the reduction in the number of US Geological Survey gauging stations. In recent years there has been a push to increase such networks as the US Natural Resources Conservation Service's snowpack telemetry gauging stations. We can see how hard it is to construct long-term records on sea-level rise, because tide gauge records have seldom been continuous.

Monitoring is as important, I believe, as expanding the horizons of research. The data sets gained are key to the expansion of knowledge as well. I monitor the mass balance of more glaciers than any other programme in North America and have done so for 25 years without any federal money. This was crucial from the start I was correctly informed that the federal government was not interested in funding long-term monitoring. As a result, I sought alternative funds that were sustainable but also enforced the use of cost-efficient techniques. Both have been key to maintaining the extensive annual fieldwork programme that is required to measure and report glacier mass balance.

\section{Mauri Pelto}

North Cascade Glacier Climate Project, Nichols College, Dudley, Massachusetts 01571, USA

\section{Restricted access to fossils hinders claim confirmation}

SIR - Your Editorial 'Replicator review' (Nature 450, 457-458; 2007), detailing the logic needed to evaluate reports of major research breakthroughs, such as the recent paper on the transfer of nuclear material in a primate, is commendable. It is responsible to require independent confirmation of 'extraordinary claims', in particular for those that are difficult to reproduce.

However, unique materials, such as fossils, require scrutiny by independent researchers to evaluate similarly extraordinary claims. Gaining access to these can be highly problematic. This issue is particularly pervasive in palaeoanthropology, where newly described fossil materials are often barred from review after initial reports. Your News story 'Anthropologists rocked by fossil access row' (Nature 428, 881; 2004) gives one example. Given that Nature is the preferred outlet for analysis of palaeontological discoveries, the editors are in a position to encourage broader access to these valuable specimens.

\section{Christopher P. Heesy}

Department of Anatomy, Midwestern University, 19555 North 59th Avenue, Glendale, Arizona 85308, USA

Readers are welcome to comment at http:// blogs.nature.com/peer-to-peer/2007/11/ peerreview_for_strong_claims_1.html

Contributions to this page may be submitted to correspondence@nature. com. Published contributions are edited. We welcome comments on publishing issues at Nautilus (http://blogs.nature. com/nautilus). 